\title{
The ambiguity of mutuality: discourse and power in corporate value regimes
}

\begin{abstract}
Corporate values offer a means for consecrating alternative regimes of worth within businesses, explicitly orienting firms around more than the pursuit of profits. This paper examines how corporate values come to be constructed and diffused as a framework for interpretation and action through analysis of Food Co.'s flagship principle: 'mutuality'. Tracing the deployment of mutuality through Food Co.'s internal processes (within the embodied practice and narratives of employees) and external relationships (within Food Co.’s bottom of the pyramid project in Kenya), the paper illustrates how the ambiguity of mutuality forms a strategic resource for the company by: (i) sheltering multiple meanings and interpretations, thus enabling resonance among different situations and subject positions; (ii) allowing for syncretism between seemingly opposing or categorically different forms; and (iii) generating a space for negotiation and dealing with uncertainty. Employing these three themes of ambiguity as an organizing frame for our discussion, we highlight how the ambiguity of corporate values absorbs the contradictions emblematic of the 'heterarchical firm' (Stark 2000), while obscuring the obligations and expectations the concept entails as it moves beyond Food Co. to outsourced 'entrepreneurs' in Kenya. Language generates the appearance of equivalence and benevolence while seeking new spaces for accumulation and legitimizing the incorporation of labor on precarious terms.
\end{abstract}




\section{The ambiguity of mutuality: discourse and power in corporate value regimes}

\section{Introduction}

As I entered the reception of Food Co. ${ }^{1}$ to observe the 'Essence of Food Co.' (EoFC) induction program, my expectations of the candy-making empire were confounded by the modest, lackluster interior. Unadorned, the entrance lobby possessed none of the upmarket furniture or professional ambience envisioned of a top tier Fortune 500 company. Rather, a single, framed poster of the company’s Five Principles —efficiency, freedom, mutuality, quality, and responsibility —assumed pride of place on the wall, illuminating their centrality to Food Co.'s corporate life. I had seen them before. While visiting Food Co.'s subsidiary in Kenya, the principles hovered above me while sitting in meetings, eating in the cafeteria, and strolling the halls. They are found on the walls of hundreds of Food Co.'s offices and sites around the world, pepper all manner of corporate communications, and are built into innumerable trainings and programs for employees and sub-contractors alike, their ubiquity rendering them both hyper-visible and inconspicuous.

The principles, I was to learn, constitute the abiding discourse of the EoFC induction program, which I had come to observe. As I joined thirty or so new employees (known as 'associates' in corporate nomenclature), representing different segments and functions across the corporation, the polished, apparently seasoned trainer announced that his role was to deepen our understanding of the principles, because they guide 'everything that we do while we work for Food Co. ... we live the principles and we live the culture, because Food Co. does things differently.' Asking participants to

\footnotetext{
${ }^{1}$ As required by our funding agreement (see footnote 2), we have replaced the names of the company, its programs and its employees with pseudonyms.
} 
consider why the principles distinguished Food Co. from its competitors, individuals retorted that at other companies values were 'just words', nondescript mission statements that failed to inspire or motivate, unlike at Food Co., where the principles guided one's everyday conduct in business. Yes, the trainer agreed, the 'principles make us fundamentally different... but what are they?' A thirtysomething male factory worker pitched in. 'The ideology of like sort of everyone's on the same level, so there's no walls in the office, everything is open-plan and all that sort of thing, which is different from other places.... everyone seems to be, even from the Director all the way down to the cleaner, everyone's on the same shop floor.' The trainer then asked what Food Co. would call this 'ideology'. A female mid-career professional chimed in, 'Mutuality.' 'Yes,' the trainer agreed, 'it's how we make mutuality live.... everybody is treated mutually. Mutuality is a shared benefit.' The participants all nodded enthusiastically, apparently sharing this mobilizing, collective vision of mutuality.

The seamless consensus presented at the training belied the disparate forms of mutuality observed and communicated in nearly all the interviews that constituted much of the fieldwork upon which this paper is based. The material symbolism of 'everyone's on the same shop floor' did not match the more important material politics of ownership and profit distribution, yet the performance of 'mutuality' succeeded in papering over the cracks between sharing values and sharing value. From 2014-2017, my colleagues and I conducted ethnographic research across the geographical spaces of Food Co. to explore how mutuality was defined and enacted as an organizing business principle. Our ethnography was part of a multi-year research collaboration on 'Mutuality in Business' between the Saïd Business School, University of Oxford ${ }^{2}$, and Food Co.'s internal think tank, Inventa; the latter

\footnotetext{
${ }^{2}$ In accordance with Springer policy, our ethical obligations as researchers, and the University of Oxford's guidelines for corporate engagement, we report that Food Co. funded the 'Mutuality in Business' program and that the company may be affected by the findings in this paper. Under the
} 
charged with spearheading a program on the 'Economics of Mutuality' that would assist the company's transition from a profit maximization to value optimization model across what they termed the 3Ps: performance, people, and planet. Our research stream, 'Conceptualising Mutuality', was concerned with understanding the meanings attached to mutuality, in both the abstract and already-existing enactments of the principle.

Central to the construction of mutuality at Food Co. was an array of 'reflexive practices' (Stark 2000), from the EoFC onboarding process, Food Co. Ambassador and Volunteer Programs, and 'Food Co. University' training courses and e-learning modules, to the micro-rituals of applying the principle of mutuality in processes of everyday decision-making. Yet such exercises often failed to clarify a distinct meaning of the principle. Rather, they opened up greater complexity and ambiguity, generating calls for further reflexivity and probing. In this open-ended and often circular process of defining and locating the value in action, mutuality grew to incorporate multiple discourses, accruing layers of meaning at times competing and contradictory. Whilst Food Co. sought this research collaboration to clarify the definition of mutuality, this definitional ambiguity was not necessarily disadvantageous to the corporation. The single word, despite its multiple meanings, was a banner under which associates could feel part of a coherent whole. As one Food Co. associate suggested:

terms of Oxford Saïd's contract with Food Co., researchers are required to carry out work within a framework of agreement that allows for academic independence, subject to respecting the anonymity of the corporation and its employees. Editorial control remains with authors. We have disclosed these interests fully to Springer. 
[in contrast to] other companies maybe where they write a manifesto or set of principles or values of a mission statement [that] sits on the wall or it sits in the drawer and no one really lives it... mutuality... holds us together as a business and the way we treat each other and the way we treat associates, the way we treat other stakeholders. So it's a very powerful narrative if it's harnessed in the right way.

As we will explore, rather than creating confusion and discordance, the ambiguousness of the meaning and deployment of mutuality served as a strategic resource for constellating unevenly shared interests, ambitions, and purposes across Food Co.’s hierarchy.

Mutuality resides in a broader landscape where values have become an essential component of corporate identity politics in the Global North. Alongside mission and vision statements, values are said to guide corporate actors-from leaders to low-ranking workers-along the righteous path toward business success. In recent years these carefully crafted statements have taken on increasingly novel forms, such as Google's long-time mantra urging employees not to be evil (Hern 2015), Starbuck's injunction to '[connect] with transparency, dignity and respect' (Wachtel 2017), and Zappos' core value to 'deliver WOW' (Hsieh 2010: 160). Fashioned to imply a corporate ethos where employees and organization are bound together and guided by a shared moral code, ${ }^{3}$ such values are strategically deployed to differentiate businesses from their peers; or as one executive cautioned, without such statements companies would 'lack soul' (Rossi 2015). More cynically, in an era of corporate ethicizing

\footnotetext{
${ }^{3}$ In addition to guiding values, companies advance multiple ethical currencies as a corporate 'good', from transparency, accountability, and empowerment, to partnership, affect, and responsibility (see Dolan and Rajak 2016, Jackall 2009, Welker 2014).
} 
(Dolan and Rajak 2016) and consumer demand for accountability and transparency, companies must increasingly present a face of 'doing good' in order to motivate employees and attract new profits.

While most companies embrace a platform of core values (Moeran and Garsten 2013), leading brands now devote hefty resources to transform them into discernible and tangible cultural assets, 'both at the levels of (embodied) practice and narrative' (Chong 2012:37). Seminars offer executives advice for how to 'walk the talk' of corporate values, while employees' performance is increasingly assessed based on the extent to which they embody a firm's principles. This increased emphasis on enacting corporate values mirrors current interest in the social and cultural processes of valuation (Boltanski and Thevenot 2006; Chong 2012; Law \& Mol 2002; Stark 2000). A central theme in this literature is an emphasis on heterarchies, plural regimes of worth that permit multiple criteria of evaluation. In Stark's (2000) work on the values-driven corporation, he argues that the 'heterarchical firm' is a vital adaptation to contemporary conditions of rapid technological change, compelling corporate management teams to master 'the art of facilitating organizations that can reorganize themselves' around competing and coexisting value systems (Stark 2000:8). Corporate values offer a means for consecrating alternative regimes of worth within businesses, explicitly orienting firms around more than the pursuit of profits.

In this paper, we use the principle of mutuality as a lens into the multiple workings of ambiguity that saturate the corporate values regime and help to legitimize the company's labor relations. Echoing the position of anthropologists such as Gallenga (2016) and Porée (2016), we seek not to render a verdict on the effectiveness of mutuality, but rather to examine the effects the language of mutuality compels. We begin by discussing ambiguity as conceptualized in anthropology, and identify three key actions performed by ambiguity. First, ambiguity shelters multiple meanings and interpretations and enables resonance among different situations and subject 
positions. Second, ambiguity allows for syncretism between seemingly opposing or categorically different forms. Third, ambiguity generates a space for negotiating uncertainty, enabling powerholders to set the rules of engagement while cloaking them beneath different sets of representations, discursive forms, and relational models. After describing how mutuality appears in Food Co.'s internal and external machinations, we employ these three actions of ambiguity as a framework for discussing the values-based corporation as premised on the strategic deployment of ambiguity. In so doing, we show how the ethical halo of mutuality allows the company to wield power, expand markets, and incorporate non-employee workers on precarious terms.

\section{The Actions of Ambiguity}

The academic literature, from linguistics to law, analyses ambiguity primarily as a property of language and communication, encoded in expressions (e.g. Wasow et al. 2005), utterances (e.g. Kennedy 2011), and other forms of discourse and text, in either strategic or non-strategic capacities (e.g. Winkler 2015). However, concepts, structures and relationships may also carry ambiguous content, form, and properties, and this ambiguity can afford certain actors more negotiating power. Our reading of a subset of the literature on ambiguity, primarily from an anthropological perspective, illustrates three ways in which ambiguity can be apprehended ethnographically and revealed to perform particular actions of relevance to Food Co.'s mutuality principle.

First, ambiguity shelters multiple meanings and interpretations and enables resonance with different situations and subject positions. Ambiguity can thus be identified as a central property of 'boundary objects' (Burrell and Oreglia 2015; Cornwall 2007; Huang 2016; Star and Greisemer 1989). Being 'both plastic enough to adapt to local needs and the constraints of the several parties employing them, yet robust enough to maintain a common identity across sites' (Star and Greisemer 1989:393), boundary objects are characterized by conceptual ambiguity, which enables the bridging 
and enfolding of diverse viewpoints. As we will show later in the paper, mutuality acts as a boundary object at Food Co., and its ambiguous conceptual content draws coherence across the corporation. This coherence is reached not through achieving consensus, however. Countering classical organizational communication theory-the prevailing ideology of which emphasizes openness, clarity, and information flow-Eisenberg $(1984,2007)$ shows how conceptual ambiguity is used strategically to accomplish particular goals, such as maintaining power hierarchies and diminishing the challenges posed by organizational diversity. Eisenberg asserts that 'strategic ambiguity promotes unified diversity' (1984:7), and that 'the 'problem' of divergent goals is not always best resolved through consensus... but instead through the development of strategies which preserve and manage these differences' (1984:8). Similarly, Batteau (2000: 726-736), drawing on the notion of bricolage, describes how disparate interests 'are spun, woven, and stitched together,' ambiguity inherent in the 'never-ending effort to impose order' within organizations.

Ambiguity's second action is to reveal syncretism between seemingly opposing or categorically different forms. Writing about Greek-Albanian border contestations, Green (2005) argues that disputed spaces are characterized by a lack of distinction and difference among people and identities; such spaces defy clear, modernist distinctions, thus rendering identity and nationality oppositions ambiguous. Green shows how states' continual attempts to resolve ambiguity by enforcing borders and separation fail violently. Thus, ambiguity alerts us to the presence not of opposing forms, but instead of a possibly uncomfortable or politically disadvantageous syncretic form. In this paper, we will highlight how ambiguity regarding whether mutuality suggests a morality-driven charitable organization or a profit-driven capitalist business entity reveals a different, syncretic form most closely resembling an uncomfortable patronage and dependency relationship. 
The third action of ambiguity is to generate a space for negotiating and managing uncertainty within relationships. When the nature of a relationship is uncertain, people expend significant effort to define categories of social relations and appropriate behaviors (Zelizer 2012). Ambiguity is a resource people use in such negotiations; yet, the space for negotiation often enables power-holders to set the rules of engagement, especially when codified systems or relations do not map neatly onto actual life situations. The practice of law, for instance, defies the clarity of rules, creating 'a zone of moral or at least pragmatic ambiguity and of room to maneuver' (Harris 1996:4), in which courts, lawyers, and other powerful interests assert their own version of acceptable action. Similarly, leaders in corporations use ambiguous language to protect their privileged positions and maintain power imbalances, because clear statements invite contestation and loss of authority (Eisenberg 1984). When enacted by less powerful actors, however, ambiguity in speech acts can be used to mitigate, challenge or protect oneself from authoritative power (Ainsworth-Vaughn 1994).

In the remainder of the paper we apply these three actions of ambiguity — enabling coordination among diverse players, structural and relational syncretism, and consolidation of corporate authority — to an analysis of the ambiguous meanings, structures, and power-infused relations of mutuality within Food Co. Focusing on mutuality as one of the central organizing principles of Food Co.'s internal processes (within the embodied practice and narratives of employees) and external relationships (within Food Co.'s bottom of the pyramid (BoP) program, Insansa), we discuss how the contemporary corporation stitches together economic and noneconomic value through all-encompassing yet ambiguous principles.

\section{Mutuality and Food Co.}

Food Co. is one of the world's largest privately owned fast moving consumer good companies, generating tens of billions in annual revenues. Uniting a complex global web of suppliers, producers, 
and distributors in over 70 countries are a set of principles that serve as 'the foundation of the culture and the approach to business' (Food Co., Internal Documents). Indeed, mutuality is cast not as a moral bolt-on to the pursuit of profits (a critique often applied to CSR programs [Rajak 2011]), but as 'putting principles into action' — a moral touchstone for working praxis.

While the principles were codified in 1983, mutuality has held a distinctive position in the company since the 1940s, originating in a short note penned by Robert Parks Sr, the director of Food Co.:

The company's objective is the manufacture and distribution of food products in such a manner as to promote a mutuality of service and benefits ... This expresses the total purpose for which the company exists - nothing less — and it is expected that the Board of Directors, all Management and employees of the company, will be motivated by this basic objective, and will keep it constantly in mind as the guiding principle for all their work in the company (cited by Badger 2014:3; underline in original).

Mutuality has since become one of the key structuring principles of the business internally, and increasingly externally, as mutuality comprises the heart of corporate ambition 'to be the most mutual company in the world'. Yet, despite the elevation of the principle, the meaning of this declaration has been the subject of much internal wrangling, spawning the research program on 'conceptualizing mutuality', upon which this paper is based. The research included: extended interviews with senior and mid-level managers on several continents (via skype), and with microentrepreneurs, field officers, program managers, and NGO partners involved in the company's BoP 
route to market program, Insansa, in Kenya; ${ }^{4}$ observation of the EoFC induction program and the Insansa selling process; and review of the training materials used by the company to inculcate new starters into the company's value system - of which 'mutuality' is the cornerstone. The Oxford-Food Co. partnership hoped this research would generate broader understandings of mutuality as an economic model and management theory, which could offer an alternative to the orientation towards 'maximizing shareholder value' of existing corporate capitalism (Lazonick \& O’Sullivan 2000). At the core of Food Co.'s interest in the project lay an ambitious vision to redefine how business performance is understood and measured. The company has already established long-term targets for sustainability, health and well-being, whose progress is measured against 'scientifically credible' metrics. Food Co.'s interest in defining and quantifying mutuality also entailed a bid to establish a metric of valuation, and thereby an evidence base, for the company's value claims within the competitive corporate landscape.

\section{Corporate Value as Boundary Object: Food Co. and the Multiple Meanings of Mutuality}

\footnotetext{
${ }^{4}$ This entailed interviews with 16 senior executives in Europe and North America. In Kenya interviews were conducted with 73 micro-entrepreneurs, 4 field officers, 10 managers/associates at Food Co.'s subsidiary, and 3 NGO staff. A further 16 photo elicitation interviews, by which individuals were asked to take and discuss photos that illustrated aspects of their work lives were carried out in April 2015. All interviews with micro-entrepreneurs were conducted in Kiswahili or a local language; all other interviews were conducted in English. All transcriptions, as well as Food Co. Inventa's archive of 'culture studies', were analyzed using NVIVO qualitative data software.
} 
Within anthropology, mutuality typically refers to the distinctive ethical and economic relationships found among members of the same kinship group, based on reciprocity and responsibility (PinaCabral 2013; Goldfarb \& Schuster 2016; Gudeman 2009). In a business context, however, its meaning is linked to mutual banks and societies, organizations owned and run for the benefit of their members, be they employees, customers, or both (Yeoman and Roll 2014). Mutuality at Food Co. is at odds with this collapsing of ownership and membership, as the company retains complete independence as a family business. We find instead a different interpretive thrust, in which mutuality serves as a cultural resource to make sense of organizational changes and enact a corporate (sub)culture. But rather than possessing a singular and stable definition, mutuality is a loadstar often befogged by differing significations. As a boundary object (Star and Greisemer 1989) mutuality is both polysemic, evoking multiple meanings and interpretations across situations and subject positions, and polyvalent, enabling resonances and exerting a combining power over these multiple meanings. Thus, rather than assuming that mutuality holds the same discursive meanings across Food Co., we trace the differences in how mutuality is used by actors within the company and its value chain. After portraying several interpretations (and ethical registers) of mutuality, we show how its definitional ambiguity stimulates an organizational need for reflexivity and abstraction, which, in turn, generates more open-ended questions and multiple meanings, thereby increasing the ambiguity of mutuality.

\section{Mutuality as reciprocal market exchange, social contract, or community patronage?}

Food Co.'s principle of mutuality has changed remarkably little since its inception over 70s years ago. Today it remains officially defined along instrumental lines, elucidated in the much-repeated notion that 'a mutual benefit is a shared benefit; a shared benefit will endure.' Building an enduring future for the company, said one manager we interviewed, is accomplished 'by making sure that whatever 
we do, however we conduct ourselves in our business, we are always being mutual to all the parties that we interact with.' Most senior managers echoed the notion of 'shared benefits,' often recast as a 'win/win,' a necessity for sustaining the partnerships Food Co. requires to operate: 'I give you something, and I also receive something for us to continue the journey together. But if it's me giving all the time, at some point I will also get tired.' 'This sharing of benefits was thin on expectations, proposing little beyond the basic tenet of market exchange-that of a mutually beneficial trade-a model of mutuality in which no structural constraints or power inequalities affect transactions, and basic free market principles apply.

Employees, however, inscribed mutuality with supplementary meanings: from calls to 'fairness' and evocations of egalitarianism, to simply treating the workforce as 'people.' The 'golden rule' was frequently cited in conversations, the moralizing summons to 'do unto others as you would have them do unto you.' 'Here, people are mutual, people speak to each other, people respect each other,' vouched one employee. Yet this discourse of equivalence was often infused with undertones of hierarchy. Workers and managers alike appealed to the concept of the 'social contract,' contending that good treatment from the company should be exchanged for worker loyalty. As an ambiguous concept, mutuality had enough discursive flexibility to be used to reinforce employees' devotion to the company. As a national sales manager asserted: 'The company has already given you a job and a good working environment, which is already mutuality because so many people are unemployed.... How can we make people understand that the company has given you a life?' In this manager's model of mutuality, corporate benevolence was to be repaid through ongoing loyalty and hard work. 'I always remind them,' said the manager, 'when a company declines and closes its door, you lose. The owner of the company has so many other things they can do, but you as an employee, you have to get another job. You shouldn't look at it from the angle that a bonus has to be given throughout, you also have to give back in order for you to benefit.' Thus, with a definitional turn, the value of 
mutuality - held up by Food Co. as its guiding principle, as the key ingredient in its corporate 'soul' could be mobilized away from corporate accountability, its ambiguity harnessed toward the responsibilization of employees.

Sharp divergences also existed in understandings of how mutuality should be applied and enacted. For some associates, the scope of mutuality was relatively unbounded, 'it's about mutuality to contractors, it's about mutuality to our locations'. For most, however, mutuality was construed as 'giving back to the community', particularly to the less fortunate. Rather than invoking reciprocalmarket-exchange and hierarchical-social-contract meanings of mutuality, these employees invoked community patronage, in which 'help' to those with less fortune and power yields dedicated followers: 'I've come to realize that mutuality is actually giving back to the community, and they in turn give back to you through being dedicated to your product and selling'. As shown in Rajak's (2011) analysis of Anglo-American's CSR program in South Africa, corporate gifts, such as student bursaries, are given with expectations of reciprocity in the form of loyalty to the platinum mine, reinforcing the giver's power and the receiver's dependency (see also Gardner 2012). This tenor underpins much of mutuality in action, to which we return in the following section.

\section{Ambiguity's valence and the drive for specificity}

Mutuality emerged from conversations across organizational ranks as a decidedly amorphous concept, reflecting the way it interacts with other espoused values and assumptions, and is often situational in terms of interpretation and enactment. Able to incorporate new associations, subsume previous incarnations, and adapt to many subject positions, mutuality at Food Co. could carry diverse meanings, to the overall effect of ambiguity regarding its content. Eisenberg describes how 'strategic ambiguity is essential to organizing because it allows for multiple interpretations to exist among people who contend that they are attending to the same message' (2007:8). For Eisenberg 
(2007) and others (Markham 1996; Leitch and Davenport 2003; March and Olsen 1976), strategic ambiguity is a deliberate managerial approach deployed for instrumental ends. Managers at Food Co., however, did not always recognize (or acknowledge) this productive feature of ambiguity. As one asserted, 'We need to find a way to define this in a more common way because, when people share definitions, it's easier... common definitions is something that allows people to connect better.' Similarly, in Royvrik's account of the creation of a value-based corporate identity at a large multinational company, he describes how principle-making was met with resistance when principles were deemed too broad and vague to capture the reality of the company's operations (2013:27). This highlights a central weakness of ambiguity: it precludes broad consensus with powerful operational definitions. While ambiguity can be used to maintain control from the top, it can also be used to maneuver against power, such that the benefit of ambiguity may give way to losses incurred through it. Accordingly, a key question underwriting the research partnership was how to make mutuality operational in a plural value system, where multiple interpretations compete for employees' attention.

The discursive practices of reflexivity about mutuality and the layers of ambiguity they produced were met by an equally active desire for quantification. Several managers said that measurement was essential to the enactment of the principles, voicing a concern that the unmeasured lacked the necessary ontological weight to legitimize its claim to existence. An absence of metrics appeared to signal an emptiness behind the rhetoric, while quantitative data would provide the evidence deemed necessary to make mutuality tangible and knowable. The drive to specify was linked with technocratic and instrumental needs to measure and benchmark against competitors, as expressed by a senior manager:

So we just had the Make The Difference Awards [...]. Well it's very nice to have prizes and a big gala and lots of regional events all costing millions and millions of dollars, [...] - but first 
of all if we're talking about mutuality, is that a good use of our money and should we be standing up there celebrating this stuff sort of, you know, what I'll call amplified, when we haven't got anything going yet to even measure it appropriately. So who's to say that my program is more mutual than yours?

Another manager asserted,

Let's be clear. It's one thing to say it, but what does it mean and how do we measure how we are progressing against those goals? What do we need to measure to ensure we are the most mutual company? We can have an internal view, and we'll believe we're the most mutual, but unless we're compared against the benchmark against our top competitors, we'll never be able to declare we're the most mutual.

Values thus discussed were portrayed as entities that 'can be added or accumulated, much like numbers on the bottom line’ (Kraus Jensen 2010: 156).

Metrics at Food Co. functioned as 'technologies of enchantment' (Gell 1988), allowing for an imaginative bridging between the known and the desired, generating a sense of control over future states, a means of knowing and a pathway for attaining (Roberts 2015). Much energy was dedicated to constructing this anticipatory knowledge through setting benchmarks, honing indicators, and fashioning data-collection systems. Evaluation itself became a subject of regular scrutiny, as numerous reports, workshops and conferences explored how best to measure human, social and natural capital, while Food Co.'s quarterly newsletter, A Byte from Food Co., posted the latest thinking on the topic. Protocols on measurement were put in place, realized through an array of datagathering tools, the 'paradigmatic artifacts of modern knowledge practices' described by Riles (2006:2). 
Without a clear and measurable definition of mutuality, Food Co.'s attempts at quantifying mutuality practices led to ambiguous results. The company's internal Culture Reports, which investigated, inter alia, organizational culture across Food Co. sites, coupled with an internal Leadership in Mutuality report, determined that mutuality was an important organizing principle, but was not always visible or clear. These exercises concluded with calls for further investigations which would explore the contingencies of mutuality, establish frameworks and guidelines, produce further discussion notes, and absorb more insights. Introspection thereby bred further introspection, hardwiring reflexivity into the fabric of a mutual Food Co., while leaving the meaning of the value ambiguous.

Despite the contradictory and unresolved tensions thrown up by this questioning, these reflexive practices offered employees a space to ponder the ethics of business practice and to perform the work of an ethical corporation. Michel Callon argues that economics 'performs, shapes and formats the economy, rather than observing how it functions' (1998:2). The reflexive exercises conducted at Food Co. performed the reality they claimed to describe: a sphere of ethical deliberation which, independent of its outcomes, helped construct the company as a principle-led organization with ethical reflection at its core (Thrift 2000). Furthermore, by making mutuality into an object of surveys and reports - and, indeed, by partnering with a leading business school to carry out this research - Food Co. sedimented mutuality's status as an operating principle, a central regime of value into which time and money were invested. Food Co. thereby not only lent credence to its claims of values-based management, but also created a discursive and material scaffolding to secure the principle of mutuality ontologically, consecrating mutuality as an 'order of worth' around which employees could justify their actions (Boltanski \& Thevenot 2006). 


\section{Not Charity, Not Business as Usual: An Ambiguous Syncretic Form}

In Marcus' analysis of the cultural corporation, he posits that 'self-conscious reassessment' indicates a retreat inward in times of increasing uncertainty (1998:7). At Food Co. however, corporate navelgazing mirrored back outward, as a growing roster of external projects was rolled out under the banner of mutuality. Through these projects, Food Co. sought to extend its ethical remit to the legions of farmers who supplied the company's cocoa in West Africa and the 'bottom of the pyramid' door-to-door sales agents who sold Food Co. products in hard-to-reach areas of Africa and Southeast Asia.

The expansion of the company's ethical remit heightened employees' struggle over the meaning of mutuality: was it charitable action, CSR work, sharing value with stakeholders, fair market exchange, or something else? In the realm of external projects, the definitional ambiguity discussed above yielded ambiguity in structural form and thus relational dynamics. Food Co. actors carefully distinguished mutuality from charity and CSR, and from single-minded profit-maximizing 'business as usual', as clear but logically opposed forms of economic action. While absolute forms of morality-driven charity/CSR and finance-driven capitalism exist only as ideologies of late capitalism, people's efforts to distance their actions from one or the other revealed local conceptualizations and theories of mutuality. The discomfort experienced by Food Co. actors over perceived structural ambiguity was a key indicator of syncretism among (ideologically constructed) opposing forms.

Mutuality in the Insansa Program: CSR or business as usual?

Insansa is the brainchild of Food Co. Inventa, which developed the pilot as a test case of mutuality in business. The program, which aims to put 'social objectives at the heart of business', provides 650 informal micro-entrepreneurs the opportunity to sell Food Co. confectionary to dukas (small retail shops) in 'hard-to-reach' slums and rural communities, considered key growth markets for the 
company. Entrepreneurs (deemed 'uplifters' by the company), who hail from these communities, were rewarded with a small commission on each product sold, supplemented with an end-of-themonth commission-based bonus. While tapping into the 'fortune at the bottom of the pyramid' is an ambition of many consumer-facing multinationals (Prahalad, 2004), Food Co. Inventa framed Insansa as a pioneering test case for the economics of mutuality, with potential for replication across emerging markets.

Employees at Food Co.'s subsidiary in Kenya, however, described Insansa alternately as a social enterprise, a philanthropic endeavor, or a sales scheme. While discursively framed through mutuality, the project accommodated diverse meanings, from the cold rationalities of 'unlocking a sustainable route to market' to moral discourses of 'doing the right thing.' One employee working closely on Insansa described her on-going efforts to remind staff that the project was about 'social benefits,' not just sales. 'There's always tension for finance and sales [department] and us at Insansa, because at Insansa, we try the social agenda more. The sales team wants to see in-market sales numbers growing higher and higher everyday, and they don't understand why we have share-outs [with entrepreneurs]. ${ }^{5}$ A senior manager in Kenya added, 'Everybody wants to jump in and say, “Okay, let's turn it into a selling tool," and I say, No, no, no, it's not a selling tool, we are looking at the social and economic benefit to the people. We have so many other tools to sell; we have our field sales rep, the other wholesalers, but this is about improving people's lives. I constantly have to keep everybody in check.' Other managers said they had to exercise oversight to ensure they did not fall back on a profit-maximization model and start taking advantage of the entrepreneurs. Such comments left much of mutuality-in-practice converging on new models of CSR, although Food Co.

\footnotetext{
${ }^{5}$ Share-outs are monthly meetings in which entrepreneurs discuss the challenges and successes of sales work.
} 
Inventa associates considered CSR a step backwards from the economics of mutuality. For example, in a PowerPoint presentation a Food Co. Inventa associate delivered to us on the evolution of the corporation's social and environmental impact, CSR was plotted as an earlier and, by implication, less-evolved iteration of the moral corporation, associated in the captions with 'writing cheques,' 'risk management,' and driving only 'some positive change.' Several Food Co. managers nonetheless remained wedded to the language and appearance of CSR and paternalistic philanthropy. 'We take them and we uplift them, fantastic, we'll give them a job, give them a livelihood, we give them a social role, we give them hope, we give them a career, we give them legacy for their family and children, fantastic,' extolled the leader of Food Co.'s training programs in the region. ${ }^{6}$ Conflicts in the enactment of values were often underplayed during the interviews; instead, managers highlighted the impacts of Insansa and other principles-led projects, framing them in humanitarian terms. As a particularly impassioned senior manager based in South Africa explained to us:

The big thing that [Insansa] does is it hits you between the eyes about the impact you can make on humanity. And I don't care if you're bloody Hitler for god's sake, you still care about people. So, you know, it doesn't matter how ruthless a businessman you are, how focused you are on.... [the] top line etc, etc, there isn't a person that hasn't seen our videos of change and been moved from, emotionally from point A to point B.

Mutuality was not only employed discursively by the company, but also constructed, performed and deployed by employees as they carved out their own claims to ethical personhood: 'I'm paid nothing from [Insansa] because I have my key job, but because of the success stories, it

\footnotetext{
${ }^{6}$ The program did not always emulate the gifting relations conjured in these accounts: most entrepreneurs reported they could not sustain themselves by selling Insansa products alone.
} 
gives me the passion to, I want to do something for someone else,' commented one Kenyan production manager, whose colleague spoke of forgoing her own targets to ensure its survival; sacrifices made in exchange for the moral satisfaction of helping those in need. Several employees in Kenya said that survival at Food Co. depended on upholding the principles. ${ }^{7}$ More commonly, however, employees said that working in the business was, as the company's website insists, 'more than a job'. As these employees described it, financial recompense was a secondary concern, and their careers at Food Co. were driven by an ethical calling. Such statements alluded to the imperative of discursively performing employment at Food Co. as an ethical project, to fit within the company's corporate culture. Mutuality was thus a 'fund of meaning', allowing individuals to tie their personal career projects, framed as moral projects, to corporate identity.

Senior managers in the Global North, however, emphasized the strategic benefits of Insansa and relegated the social-impact objectives of the project to the background:

A mutual benefit is that essentially the sales that we're getting from Insansa are from places that our products were not reaching. And so this is about... new routes to market for us as well as the... societal-transformation things that come of that, but it's about our products being successful, it's about getting to places that we wouldn't be able to get through for our new traditional routes to market.

Staking the 'business case', one senior leader commented: 'One thing that has really kept us in the game is that it's not a charity.' Indeed, some senior leaders seemed uncomfortable speaking about

\footnotetext{
${ }^{7}$ The cynicism highlighted in other accounts of corporate attempts at value-creation (Krause-Jensen, 2011; Royvrik, 2013) was largely absent; employees represented the company in a decidedly positive light, even under conditions of anonymity.
} 
mutuality and preferred to talk in terms of growth. In the words of one regional president, 'I could work with growth we're proud of, that would be sufficient to me,' and leave the 'principles where they are.... I think mutuality only exists when we're talking about growing the pie, you know, about having the ability to make what we do bigger than what it is today.' According to one senior leader, 'Food Co. is, my view is acting more like an NGO although they're a for-profit. And the problem when you do that in this world, you know, you might disappear in the long run.' Indeed, it is precisely the tension between the pursuit of economic activity 'for its own sake' (i.e., competition and growth) as opposed to 'for the sake of something else' (i.e., mutuality broadly defined), that rendered mutuality ambiguous. The reluctance of some senior management to engage with the social-impact aspects of mutuality also underscored power differentials within the company: while employees deployed mutuality discourses as part of ethical selfhood, senior managers appeared exempt from these requisite corporate performances.

\section{Mutuality as syncretic form: BoP Entrepreneurs}

Careful explanations that Insansa was neither straightforward business nor charity revealed the syncretism of the project and the anxiety it provoked. In contrast to Kunda's (1992) ethnography of management ideology, which describes how low-level engineers drew on irony to stake out their autonomy in the face of relentless corporate propaganda, entrepreneurs in Insansa interpreted the relationship with Food Co. as one of patronage, and continually performed 'declarations of dependence' (Ferguson 2013) to invoke what they saw as proper patronage behavior. This model of economic action combined hierarchical largesse and transactional exchange, in which loyalty and labor are exchanged for resources and protection, thus revealing the deep syncretism of the two forms Food Co. Inventa claimed Insansa was not. Because entrepreneurs inhabited a post-colonial social and economic world where dependence (Bayart 2000), patronage (King and Van Zwanenberg 
1975), and everyday social claims making were familiar and well-understood relational categories, they did not experience the anxiety with it that Food Co. Inventa associates did, and saw Food Co. as possessing the resources and the obligation to mitigate the challenges they confronted in their dayto-day work.

Two examples reveal the ways in which entrepreneurs interpreted the relationship to be patron-clientage. First, while Food Co. extended end-of-the-month commissions to entrepreneurs commensurate with their sales outputs and according to the logic of reciprocal market exchange, entrepreneurs spoke about commissions through idioms of patronage. Perceiving commission as a special windfall or bonus, separate from daily earned income, entrepreneurs construed this monthly payment as a gift expressing corporate gratitude for their loyalty. As one entrepreneur explained, 'When you join Insansa and you sell packets, then there is a profit we normally make, and then there is a commission that they give us at the end of the month to show that they appreciate [us].' The language of 'giving' was routinely used to differentiate this end-of-the month money (also referred to as 'incentives') from everyday sales earnings. The delayed temporality of commission, and the longerterm social relation this implied, also invoked patronage. While daily income was spent on daily expenses, entrepreneurs earmarked their commission money for special expenses such as paying into socially organized savings groups and upgrading their equipment or transportation.

Second, entrepreneurs sought durable connection with the company in which risk mitigation and the costs of overcoming structural barriers were shared. Entrepreneurs routinely requested items such as gumboots, rain coats, umbrellas, and bags to protect their products from the rain; more 
efficient forms of transportation such as bicycles ${ }^{8}$ and motorcycles; and branded ware to advertise their products and lend the appearance of professionalism. Other companies provided such forms of assistance, which established a precedent of expectation among the entrepreneurs. Entrepreneurs also hoped their loyalty would eventually translate into employment: 'They are good people. They told us that we put effort in the work and they can employ us; when an opportunity comes, they will give us. That is why we are working hard because we know they will not just leave us like that.' Describing the role patronage plays in a social enterprise in Bangladesh, Huang (2016:25) writes that 'To deny requests [for gifts] is to fail or refuse to recognize the relational and moral claim underpinning the request', in this case mutuality. This highlights the boundaries of mutuality, and the strategic undercurrent that fueled its continued ambiguity despite a corporate objective to clarify it.

Notably, entrepreneurs were not aware of mutuality being a driving principle behind the company's relationship with them. The term 'mutuality' was not mentioned by the entrepreneurs we observed and interviewed, conveying the restricted access that entrepreneurs had to the discourses of the company's own values, and their role as recipients, rather than enactors, of mutuality. In our discussions, rather than speaking directly of mutuality, the entrepreneurs invoked relational logics that were compatible with the concept, expressed concisely by one as 'the roof grows, and I grow.' As many entrepreneurs indicated in various ways, 'It's possible I can ask for these gifts. [I can ask for] a bicycle, then come to a motorcycle and then to a car. Because [Food Co.] is also growing. The more we sell, the more [Food Co.] also gets their money.' Entrepreneurs thus invoked a logic of economic action whereby the company's mitigation of structural barriers would improve their selling position and yield benefits to both parties: a syncretic model that resembled patron-clientage,

\footnotetext{
${ }^{8}$ A program that provides entrepreneurs with access to bicycles through the provision of microcredit commenced in 2018.
} 
combining aspects of charity (through gift giving and protection) and business (through the sales relationship and profit sharing).

\section{Space for Negotiation or Consolidation of Power? Ambiguity in Hierarchical Relations}

\section{Insansa and the 'gift' of subjectivity}

As noted, Food Co. and Food Co. Inventa worked hard to differentiate the principle of mutuality from CSR and charity, with employees invoking a logic of disconnection in which the company's role was to help the entrepreneurs help themselves (see Gardner 2012). According to this rhetoric, entrepreneurs benefited through becoming 'better people' rather than through receiving gifts or other tangible forms of help. A manager in Food Co.'s Kenya subsidiary demonstrated this logic, portraying patronage as a 'selling tool,' in contrast to a strict market regime dedicated to 'changing people's lives' through mutuality. She compared Food Co. with competitor companies who said to their distributors, “We are giving you motorbikes and we'll give you free credit,” because for them it's only selling, they're not doing the mutuality part of it. But we [at Food Co.] are looking at how are we going to change people's lives.' According to this valuation of self-sufficiency, and the educative stance that underlay it, people needed to invest themselves and their money to feel a sense of ownership, whereas they would fail to value things given freely as gifts, as these might establish dependency. The rationalized market relationship, detached from affect and charity, ensured that upliftment entailed relatively ephemeral bonds between Food Co. and the entrepreneurs (see Cross 2011). 
Managers of Insansa, for instance, considered requiring entrepreneurs to pay a fee for their training so that they would 'own the paper' (meaning training certificates), and did not compensate entrepreneurs for earnings forfeiture by attending training sessions ${ }^{9}$ and other Insansa events. As a sales manager noted, 'When we went to launch [the program], everybody wanted a sitting allowance. ${ }^{10}$ I told them "no, if I give you a job which is selling this product, where you keep the money for you, and I give you this much at the end of the month, I'll make you a better person than you getting two hundred sitting allowance." Similarly, when entrepreneurs experienced illness, product damage, or theft, they received encouragement rather than help with cash flow to overcome the immediate crisis. 'Sometimes some of them get mugged, their products stolen, some fall sick for months on end because their bag is heavy, they are being rained on, there are terrible weather conditions.... If they're sick, we might not give them money, but even giving them a call and telling them "you'll get well soon" is quite enough to keep them going,' a national sales manager reasoned. If entrepreneurs were supported fully by the company, 'they'd make it a habit', and if they did not succeed in the Insansa program, it was because they had forsaken the opportunity given to them: 'You're going to work hard and you're going to benefit and you're going to grow and we're going to give you opportunities, and it's your choice whether you take those opportunities or not, fine.' This interpretation of mutuality encompassed a neoliberal entrepreneurial subject, who must respond to the moral exhortation to 'help oneself by embracing the opportunities provided by business

\footnotetext{
${ }^{9}$ The company recently introduced mobile money payments so that entrepreneurs would no longer have to attend 'share out' sessions, where bonuses are distributed and training occurs (Radvan and Roche 2017).

${ }^{10}$ A sitting allowance is payment to attend meetings, a common practice among government and donor agencies in East Africa.
} 
initiatives such as Insansa, to become, as Gordon (1991: 44) puts it, 'an entrepreneur of himself or herself. That mutuality could contain - and indeed, be used to justify - a discourse of self-help, whilst maintaining its plausibility as a value, points both to mutuality's conceptual flexibility, and to the broader neoliberal construction of 'good citizenship' as premised on individuals' successful management of insecurity in the post-CSR era.

By designating BoP projects an exercise in external mutuality, Food Co. indicated that these projects were not designed to incorporate entrepreneurs into the Food Co. family, ${ }^{11}$ with its attendant rights and responsibilities. Rather, Food Co. would preserve the 'voluntary ethics' (Shamir 2004) of benefaction between the business and the Insansa entrepreneurs. At the same time, mutuality was mobilized to lend value to corporate routes into the Global South that might otherwise be seen as less ethically creditable. Ultimately, Food Co. invoked particular representations as its needs dictated, whether to deny declarations of dependence (Ferguson 2013) and requests for tangible help from entrepreneurs, or to assert its own moral position in helping to improve the lives of disadvantaged people. The structural and content-related ambiguity of this relationship and the project in general enabled these multiple forms and meanings to coexist, ready to be mobilized to fit organizational and employee agendas. The power to define value remained with Food Co., and practical negotiations favoring other forms of value and understandings of mutuality were yet to surface.

\section{Conclusion}

\footnotetext{
${ }^{11}$ See Kondo's (1990) account of a family enterprise in Japan, which highlights how kinship idioms are deployed for normative control by owners, but also strategically appropriated by the workforce for their own ends.
} 
Corporations increasingly direct resources toward translating ambiguous corporate values into realizable cultural assets. As this paper has shown, the ambiguity of corporate values is entangled with power differentials and organizational hierarchies, such that, despite apparent efforts at defining and quantifying regimes of value, corporate values remain slippery, their very ambiguity serving to maintain a multiplicity of sometimes-conflicting interests across company strata.

In tracing Food Co.'s bid to embed mutuality as a central organizing principle of corporate practice, our ethnographic work found resonances with earlier research on the cultural corporation (Marcus 1998), which showed that efforts at consecrating corporate values are often tied to diverse and extended reflexive exercises (Stark 2000). At Food Co., the imaginative relationships conjured through such practices allowed employees to perform the work of the principles-led corporation, inscribing certain institutional, professional and personal practices as mutual. Moreover, trainings, data collection tools and evaluation methods targeting mutuality formed a system of representation that commanded its own authority, 'hailing' employees as part of Food Co.'s broader moral project (Chong 2012). Through such ethical deliberation, mutuality was secured as an operating principle and basis for social action, serving as a boundary object capable of absorbing contradictions emblematic of the 'heterarchical firm' (Stark 2000). Yet introspection generated further calls for reflection, in a spiraling process of (in)definition, and despite concerted efforts to stabilize mutuality, it is precisely its lack of specificity that has sustained its presence across the company (Eisenberg 2007).

When it came to enacting mutuality, hierarchies of power emerged. Practical instantiations of mutuality allowed the production of 'real-world' narratives with moral resonances, such as employees' claims to moral personhood. However, when the principle travelled to the entrepreneurs positioned outside of Food Co. - the slated beneficiaries of its externally-focused, mutuality-driven business in Kenya - mutuality was performed in a territory of symbolic and material inequality. 
Annexing mutuality to contemporary concerns with the disadvantaged ends of global value chains underscored the gulf between Food Co.'s own brand of mutuality as a path to sustainable corporate gains, and the term as understood within anthropology (Gilbert and Dolan nd), with resonances of commensurability, reciprocity, and structural reconfigurations of power.

What does our analysis add to anthropological analyses of ambiguity? First, by examining the content behind Food Co.'s principle of mutuality and its enactment in varying contexts, we reveal multiple models of economic action operative within the corporation. A primary action of ambiguity is to conceal the multiplicity and contradictory nature of different models of economic action, drawing together people with multiple agendas and coalescing seemingly incompatible perspectives. Ambiguity is thus expansive and inclusive: it widens the arena of play, enables the enrolment of players with diverse understandings, and provides a space for negotiation of meanings. But when we take corporate power into consideration, we find that the space for negotiation enables powerholders to set the rules of engagement, thus exercising what Lukes (1974) regards as the third face of (ideological) power-how those who hold power shape the perceptions, cognitions, and preferences of those who do not- - even if it seems ambiguity is not being used deliberately for this effect.

Second, values in the new cultural corporation emerge as ambiguous artefacts whose meanings vary according to discursive context. The meanings, relations, and structures to which mutuality is attached convey different ideologies and ethics of work, relationality, and causal understandings of 'upliftment' or 'social impact'. Mutuality thus performs different work for different positions in the corporate hierarchy. For the Food Co. family and senior managers in the Global North, mutuality produced financial benefits; for employees, the performative discourse of mutuality generated ethical personhood and moral sustenance, whilst reinforcing their position in the corporation. In contrast, entrepreneurs, as targets of programs where mutuality was explicitly enacted, were excluded from 
mutuality's discursive regime. What counted as 'mutuality' for entrepreneurs was rooted in different arenas of socialization and identification (i.e., local communities and moral economies) where the power-inflected relationship between patron and client formed a familiar register of exchange, with mutuality in business and mutuality in social relations deeply imbricated. For entrepreneurs, whose declarations of dependence exhorted the company to share the benefits and risks of economic action, mutuality materialized as a property of a patronage relationship rather than an approach to doing business (Gilbert et al. 2016).

Thus, values, in their ambiguity and floating signification, can enable the semblance of ethical, principled, and deliberate action while concealing asymmetric relations and vernacular meanings and expectations. Values-based management relies on the firm to adapt heterarchically, thereby attaching core values to the plural regimes of meaning and worth that circulate through the organization. The ambiguity surrounding their content and application allows the semblance of agreement and hence coherence. However, when we turn to actors framed as explicit beneficiaries of corporate values, the affordances of ambiguity come into question. Though mutuality was sufficiently elastic to accommodate the myriad valuations of employees, constellating them in the broader moral project of the corporation, the interpellative capacity of mutuality failed to resonate similarly with Kenya's BoP entrepreneurs. Dominant, official, 'elite' meanings of mutuality overshadowed vernacular meanings and situated knowledge, and the prism through which Insansa entrepreneurs interpreted their relationship with the company was an economic model premised on asymmetries, a system of patronage that reflected the syncretism of the two forms - profit maximizing business and charitythat managers vehemently asserted Insansa was not. The limits to strategic ambiguity became apparent at the bottom of the pyramid, as conflicting relational logics and unevenly shared power between those within and outside the company unsettled the ideal of commensurability Food Co. sought to enact. For those laboring at the margins of the value chain, it is through relational and 
structural clarity, and participation in the process of defining mutuality, rather than ambiguity, that a new form of capitalism founded on mutual values can emerge.

\section{References}

Ainsworth-Vaughn, Nancy. 1994. Is that a rhetorical question? Ambiguity and power in medical discourse. Journal of Linguistic Anthropology 4(2): 194-214.

Badger, Stephen. 2014. Editorial: Exploring mutuality. The Brewery 1: 2-3.

Batteau, Allen. 2000. Negations and ambiguities in the cultures of organization. American Anthropologist 102(4): 726-740.

Bayart, Jean-Francois. 2000. Africa in the world: A history of extraversion. African Affairs 99: 217267.

Boltanski, Luc and Laurent Thévenot. 2006. On justification: Economies of worth. Translated by Catherine Porter. Princeton: Princeton University Press.

Burrell, Jenna and Elisa Oreglia. 2015. The myth of market price information: Mobile phones and the application of economic knowledge in ICTD. Economy and Society 44(2): 271-292.

Callon, Michel. 1998. Introduction. In: The Laws of the Markets, ed. M. Callon, 1-57. Oxford: Blackwell,. Chong, Kimberly. 2012. The work of financialisation: An ethnography of a global management consultancy in post-Mao China, PhD Thesis, London School of Economics and Political Science, UK.

Cornwall, Andrea. 2007. Buzzwords and fuzzwords: Deconstructing development discourse. Development in Practice 17(4): 471-484. 
Cross, J. 2011. Detachment as a corporate ethic: Materializing CSR in the diamond supply chain. Focaal 60: 34-46.

De Pina-Cabral, J. 2013. The two faces of mutuality: Contemporary themes in anthropology. Anthropological Quarterly 86(1): 257-275.

Dolan, Catherine and Dinah Rajak. 2016. The anthropology of CSR. Oxford: Berghahn. Eisenberg, Eric. 1984. Ambiguity as strategy in organizational communication. Communication Monographs 51(3): 227-42.

Eisenberg, Eric. 2007. Strategic ambiguities: Essays on communication, organization, and identity. Thousand Oaks: Sage Publications.

Ferguson, James. 2013. Declarations of dependence: Labor, personhood, and welfare in South Africa. Journal of the Royal Anthropological Institute 19(2): 223-242.

Gallenga, G. 2016. The anthropology of business ethics: worth thinking about! Journal of Business Anthropology S3: 7-19.

Gardner, Katy. 2012. Discordant development: Global capitalism and the struggle for connection in Bangladesh. London: Pluto Press.

Gell, Alfred. 1988. Technology and magic. Anthropology Today 4(2): 6-9.

Gilbert, Paul and Catherine Dolan. nd. Mutuality talk in a family-owned multinational: Anthropological categories \& critical analyses of corporate ethicizing. Unpublished manuscript. Gilbert, Paul, Catherine Dolan, and Bojan Angelov. 2016. Conceptualising mutuality: Workstream 1 Draft Update Paper. Oxford: Said Business School. Goldfarb, Kathryn and Caroline Schuster. 2016. Introduction: (De)materializing kinship - holding together mutuality and difference. Social Analysis 60(4): 1-12. 
Gordon, Colin. 1991. Government rationality: An introduction. In The Foucault effect: Studies in governmentality, eds. G. Burchell, G. Gordon, and P. Miller, 1-52. Chicago: Chicago University Press.

Green, Sarah. 2005. Notes from the Balkans: Locating marginality and ambiguity on the Greek-Albanian border. Princeton: Princeton University Press.

Gudeman, Stephen. 2009. Necessity or contingency: Mutuality and market. In Market and Society: The Great Transformation Today, eds. C. Hann and K. Hart, 17-37. Cambridge: Cambridge University Press. Harris, Olivia. 1996. Introduction: Inside and outside the law. In Inside and Outside the Law: Anthropological Studies of Authority and Ambiguity, ed. O. Harris, 1-18. London: Routledge.

Hern, Alex. 2015. Where Google said 'don't be evil', Alphabet just wants employees to 'obey the law'. The Guardian, October 5, 2015.

Hsieh, Tony. 2010. Delivering happiness: A Path to profits, passion, and purpose. NY: Grand Central Publishing.

Huang, Juli. 2016. 'Do it yourself development: Ambiguity and relational work in a Bangladesh social enterprise, PhD Thesis, London School of Economics and Political Science, UK. Jackall, Robert. 2009. Moral mazes: The world of corporate managers. Oxford: Oxford University Press. Kennedy, Christopher. 2011. Ambiguity and vagueness: An overview. In The Handbook of Semantics, C. Maienborn, K. von Heusinger, and P. Portner, 507-535. Berlin: Mouton de Gruyter..

Kondo, Dorrine. 1990. Crafting selves: Power gender and discourses of identity in a Japanese workplace. Chicago: Chicago University Press.

Krause-Jensen, Jakob. 2011. Ideology at work: ambiguity and irony of value-based management in Bang \& Olufsen. Ethnography 12(3): 266-289.

Krause-Jensen, Jakob. 2010. Flexible firm: The design of culture at Bang \& Olufsen. Oxford: Berghahn. 
Kunda, Gideon. 1992. Engineering culture: Control and commitment in a bigh-tech corporation. Philadelphia: Temple University Press.

Lazonick, William and Mary O'Sullivan. 2000. Maximizing shareholder value. Economy and Society $29(1): 13-35$.

Law, John and Anne Marie Mol (eds). 2002. Complexities: Social studies of knowledge practices. Durham, NC: Duke University Press.

Leitch, Shirley and Sally Davenport. 2003. Strategic ambiguity in communicating public sector change. Journal of Communication Management 7(2): 129-139.

Lukes, Steven. 1974. Power: A radical view. London: Macmillan Press.

March, James and Johan Olsen. 1976. Ambiguity and choice in organizations. Bergen: Universitetsforlaget. Marcus, George (ed). 1998. Corporate futures: The diffusion of the culturally sensitive corporate form. Chicago \& London: University of Chicago Press.

Markham, Annette. 1996. Design discourse: A critical analysis of strategic ambiguity and workplace control. Management Communication Quarterly 9(4): 389-421.

Moeran, Brian and Christina Garsten. 2013. Business anthropology: Towards an anthropology of worth. Journal of Business Anthropology 2(1): 1-8.

Porée, L. 2016. Business ethics as ethical self-promotion? How advertising executives promote their activity. Journal of Business Anthropology S3: 54-64.

Prahalad, CK. 2004. The fortune at the bottom of the pyramid: Eradicating poverty through profits. Upper Saddle River, N.J: Wharton School Publishing.

Radvan, Hannah and Jean Roche. 2017. Mars, incorporated: Maua Programme. Oxford: Said Business School, University of Oxford.

Rajak, Dinah. 2011. In good company: An anatomy of corporate social responsibility. Stanford: Stanford University Press. 
Riles, Annelese. 2006. Introduction. In Documents: Artifacts of modern knowledge, ed. A. Riles, 1-38. Ann Arbor, MI: University of Michigan Press..

Roberts, Simon. 2015. Models of enchantment and the enchantment of models. Journal of Business Anthropology 4(1): 158-164.

Rossi, Holly. 2015. 7 Core values statements that inspire. Fortune, March 13, http://fortune.com/2015/03/13/company-slogans/. Accessed 5 August, 2016.

Røyrvik, Emil. 2013. Incarnation Inc.: Managing corporate values. Journal of Business Anthropology 2(1): $9-32$.

Shamir, Ronen. 2004. The de-radicalization of corporate social responsibility. Critical Sociology 30(3): 669-689.

Star, Susan and James Griesemer. 1989. Institutional ecology, 'translations' and boundary objects: Amateurs and professionals in Berkeley's museum of vertebrate zoology, 1907-39. Social Studies of Science 19(3): 387-420.

Stark, David. 2000. For a sociology of worth. Working Paper Series, Center on Organizational Innovation, Columbia University, New York. http://www.columbiacoi.com/media/papers/stark_fsw2.pdf Thrift, Nigel. 2000. Performing cultures in the new economy. Annals of the Association of American Geographers 90(4): 674-692.

van Zwanenberg, R. with A. King. 1975. An economic bistory of Kenya and Uganda, 1800-1970. Atlantic Highlands, NJ: Humanities Press.

Wachtel, Thomas. 2017. 5 Companies with core values that stand above the rest, https://elementthree.com/blog/5-examples-of-companies-with-awesome-core-values/ 
Wasow, Thomas, Amy Perfors, and David Beaver. 2005. The puzzle of ambiguity. In Morphology and the Web of Grammar Essays in the Memory of Steven G. Lapointe, eds. C. Orhan Orgun and P. Sells, 265282. Stanford: CSLI Publications.

Welker, Marina. 2014. Enacting the corporation. Berkeley: University of California Press.

Winkler, Susanne. 2015. Exploring ambiguity and the ambiguity model from a transdisciplinary perspective. In Ambiguity: Language and Communication, ed. S. Winkler, 1-28. Berlin: Gruyter. Yeoman, Ruth and Kate Roll. 2014. Understanding Mutuality and Mutual Organisation Design. Draft paper.

Zelizer, Viviana. 2012. How I became a relational economic sociologist and what does that mean? Politics \& Society 40(2): 145-174. 